\title{
Air quality classification and its temporal trend in Tehran, Iran, 2002-2012
}

\author{
Raheleh Saniei, ${ }^{1}$ Ali Zangiabadi, ${ }^{1}$ Mohammad Sharifikia, ${ }^{2}$ Yousef Ghavidel ${ }^{3}$ \\ 'Department of Urban Planning, Faculty of Geography and Planning, University of Isfahan; \\ ${ }^{2}$ Department of Remote Sensing, Tarbiat Modares University, Tehran; \\ ${ }^{3}$ Department of Physical Geography, Tarbiat Modares University, Tehran, Iran
}

\begin{abstract}
Airborne particulate matter with a diameter of 2.5 microns or less $\left(\mathrm{PM}_{2.5}\right)$, as well as slightly bigger particles $\left(\mathrm{PM}_{10}\right)$, arrive from the westerly direction and collect in the city centre of Tehran, the capital of Iran. The statistical characteristics and daily trend of the air quality index (AQI) in Theran were studied over an 11-year period (20022012). Various statistical analyses were applied including descriptive statistics, correlation analysis, trend analysis and the sequential nonparametric Mann-Kendall test. The significance of the series was investigated by regression analysis and Kriging interpolation. It was found that Tehran's daily AQI increased by $11.8 \%$ over the study period, with the frequency distribution of days with good and average air quality showing a strongly declining trend. The AQI of Tehran was shown to contain a large part of $\mathrm{PM}_{10}$ and $\mathrm{PM}_{2.5}$, the latter having the largest contribution (coefficient $=0.853$ ).
\end{abstract}

\section{Introduction}

Air quality $(\mathrm{AQ})$ and its temporal and spatial variations in a region are largely determined by the nature of anthropogenic activities associated with gaseous and particulate emissions in combination with local prevailing meteorological conditions. Epidemiological studies have established the association between air pollution and increased mortality (Dockery and Pope, 1994) as well as morbidity (Kassomenos

Correspondence: Raheleh Saniei, Department of Urban Planning, Faculty of Geography and Planning, University of Isfahan, Isfahan, Iran.

Tel: +98.21 .77602838 - Fax: +98.21 .82883617 .

E-mail: crisismanagement2008@gmail.com

Key words: AQI; Air pollution; $\mathrm{PM}_{10} ; \mathrm{PM}_{2.5}$; Time series analysis.

Received for publication: 14 December 2015.

Accepted for publication: 14 January 2016.

(C) Copyright R. Saniei et al., 2016

Licensee PAGEPress, Italy

Geospatial Health 2016; 11:442

doi:10.4081/gh.2016.442

This article is distributed under the terms of the Creative Commons Attribution Noncommercial License (CC BY-NC 4.0) which permits any noncommercial use, distribution, and reproduction in any medium, provided the original author(s) and source are credited. et al., 2008). Poor AQ has acute as well as chronic health impacts (Nastos et al., 2010), the severity of which largely depends on the ambient concentration of the air pollutant in question and the time of exposure. While the latter is relatively clear-cut, the former varies depending on local topography, source emission and surrounding meteorological conditions. Out of these, the meteorological variables are mostly responsible for the variation in the ambient concentrations of air pollutants (Banerjee et al., 2011).

Concern about air pollution in urban regions is receiving increasing importance worldwide (Chattopadhyay et al., 2010). The urban areas might be viewed as a dense source of anthropogenic emission of pollutants altering the atmospheric composition and chemistry in its downwind regimes that can extend several hundred $\mathrm{km}$ from the source (Gupta et al., 2008). Petrol and diesel engines of motor vehicles emit a wide variety of pollutants, principally oxides of nitrogen $\left(\mathrm{NO}_{\mathrm{x}}\right)$, which exert an increasing impact on urban AQ (Mage et al., 1996). Urban air pollution in Iran has increased rapidly with the growth of population, number of motor vehicles and use of fuel with poor environmental concert. Inadequate transportation systems, poor land use patterns and, above all, ineffective environmental regulations add to the problems. A better understanding of the nature of sources of air pollution and the influence of meteorological conditions on $\mathrm{AQ}$ profiles is urgently required to guide the development of appropriate strategies for air pollution prevention. As for the health impact of air pollutants, the $\mathrm{AQ}$ index $(\mathrm{AQI})$, defined as an indicator of the daily combined effect of the ambient air pollutants (Kumar and Goyal, 2011), can easily be understood by the general public and thus constitute a useful basis for decision-making with respect to pollution mitigation, thereby instituting improved environmental management. The AQI not only provides a measure on how clean or polluted the air is, but it also accounts for its associated health effects.

Many published studies focus on the air problems of urban areas because of their special importance and challenges (Junk et al., 2003). Some research compares AQ trends in different metropolitans areas (Wise and Comrie, 2005; Chang and Lee, 2007; Firdaus and Ateeque, 2011; Moradi Dashtpagerdi et al., 2014), the spatio-temporal analysis of urban air pollution (Chan et al, 2009; Yao and Lu, 2014) or urban activities, such as traffic and land use (Branis, 2009; Bandeira et al., 2011). Others deal mainly with the various sources of atmospheric pollutants (Shu et al., 2001; Singh et al., 2013) or air pollution as a consequence of rapid urban expansion (Zhao et al., 2006). It is well documented that there is a strong link between air pollution and specific human health outcomes (Hyun Shin et al., 2009; Naddafi et al., 2012; Vanos et al., 2014). Numerous studies show that among air pollutants, particulate matter (PM), especially with diameters of 10, 2.5 microns or less (PM2.5), have the strongest links with human health effects (Lary et al., 2014).

Air pollution of metropolitan areas is one of the major problems of the world at present. In Tehran, it has been created by population 
growth and industrial development. Tehran, the capital of Iran, has a population of approximately 13 million people. Located at $35^{\circ} 42^{\prime} \mathrm{N}$ and $51^{\circ} 25^{\prime} \mathrm{E}$ with an area of $2300 \mathrm{~km}^{2}$, the city is situated in a semienclosed basin just south of the Alborz Mountain chain (with an average height of $2000 \mathrm{~m}$ ). Tehran has suffered from poor air quality since the oil boom decade of the 1970s and over the last fifteen years rapid population growth has made matters even worse. On some days, the pollution loading of the atmosphere is so high that the impressive Alborz Mountains become invisible from most vantage points. Tehran's Clean Air Committee stated recently that 10,000 people die every year in cardio-pulmonary disease due to air pollution. Tehran's level of air pollution exceeds the world standard for acceptable $A Q$ and the Government of the Islamic Republic of Iran has identified the pollution as a high priority environmental and health challenge. An important cause of air pollution are the 70,000 industrial units operating within the metropolitan area and the exhaust from about 0.5 million motorcycles and close to one million other kinds of motor vehicle that operate in the extremely congested road space of Tehran (the average vehicle speed is below $18 \mathrm{~km} / \mathrm{h}$ ). Between 65 to $70 \%$ of the total emissions are related to urban transport operations (Bohler et al., 2002). The reported average concentrations of pollutants such as carbon monoxide (CO), sulphur dioxide $\left(\mathrm{SO}_{2}\right)$ and particulate matter $\left(\mathrm{PM}_{10}\right.$ and $\left.\mathrm{PM}_{2.5}\right)$ recorded in the city centre in 2007 were two to three times above the average levels recommended by the World Health Organization (WHO) and the United States Environmental Protection Agency (USEPA) (Gharagozlou et al., 2014). The growth in the number of vehicles over the last two years has made the situation even more severe.

The present research deals with temporal AQ classification and analysis over the Tehran metropolis based on local standards. Moreover, AQI measurements of the city will be extracted over the different sub-areas. The temporal and spatial AQ during one decade (2002-2012) is expected to provide grounds for analysis and major trends of air pollutants.

\section{Materials and Methods}

Data from $36 \mathrm{AQ}$ monitoring stations in Tehran (Figure 1) were selected for the current study on air pollution. The monitoring data used included hourly data on $\mathrm{SO}_{2}, \mathrm{CO}, \mathrm{NO}_{\mathrm{x}}, \mathrm{O}_{3}, \mathrm{PM}_{10}$ and $\mathrm{PM}_{2.5}$ over the 11-year period, 2002-2012. The most polluted days were chosen to show the spatial pattern of the AQI. Due to the fact that in some years the network of monitoring stations did not cover the whole area of Tehran, three years $(2009,2010$ and 2011) were selected for the spatial pattern.

\section{Air quality index}

The AQI is an index for reporting daily air quality. It tells us how clean or polluted the air is and what associated health effects might be of concern.

The daily AQI was calculated based on the average concentrations of air pollutants at all of the 36 stations were used to obtain percentages of number codes during the desired averaging periods. The air quality index is a piece-wise linear function of the pollutant concentration. At the boundary between AQI categories, there is a discontinuous jump of one AQI unit. Equation 1 (Mintz, 2009) was used to convert from concentration to $\mathrm{AQI}$ :

$$
A Q I=\frac{A Q I_{H i}-A Q I_{L o}}{B P_{H i}-B P_{L o}} *\left(C p-B P_{L o}\right)+A Q I_{L o}
$$

where $\mathrm{AQI}=$ air quality index for the pollutant; $\mathrm{AQIHi}=$ the $\mathrm{AQI}$ value corresponding to $\mathrm{BPHi}$;QILo=the $\mathrm{AQI}$ value corresponding to BPLo; $\mathrm{BPHi}=$ the breakpoint that is greater than or equal to $\mathrm{CONC} ; \mathrm{BPL}=$ the breakpoint that is less than or equal to $\mathrm{CONC}$; and $\mathrm{Cp}=$ concentration of the pollutant.

The AQI varies from 0 to 500 . The higher the AQI value, the greater the level of air pollution and the greater the health concerns. An AQI value of 100 generally corresponds to the air quality standard for the pollutant, which is the level that the Environment Protection Authority (EPA) has set to protect public health (Mintz, 2009). AQI values below 100 are generally thought of as satisfactory (Mohan and Kandya, 2007). When AQI values are above 100 , air quality is considered to be unhealthy, at first for certain sensitive groups of people, then for everyone as the AQI values get higher. The breakpoint concentrations (high and low) are adjusted to of Iran's ambient standard for each of the pollutants (Mintz, 2009).

\section{Spatial interpolation}

In the most general sense, spatial interpolation provides a valuable tool for better understanding of air quality and the extent of our nation's air pollution problems. Among other applications, spatial interpolation models can be used to define the spatial extent of episodes of unhealthy air quality, to illuminate relationships between different air pollutants and to aid in the design of $\mathrm{AQI}$ monitoring systems. However, the degree to which such models can be developed in a successful, applicable manner may strongly depend on the air pollutant in question. Put another way, the chemical properties and atmospheric fate and transport of certain pollutants may present unique problems with important ramifications for spatial interpolation modelling.

This study used several spatial interpolation techniques. These techniques include inverse distance weighting (IDW), global polynomial interpolation (GPI), local polynomial interpolation (LPI), radial basis functions (RBF), simple Kriging (SK), ordinary Kriging (OK) and universal Kriging (UK). Kriging is a geostatistical spatial (and potentially also temporal) interpolation method that derives predicted values based on the distance between points in space and treats variation between measurements as a function of distance. Ordinary Kriging - a version of Kriging that assumes the mean as constant but unknown

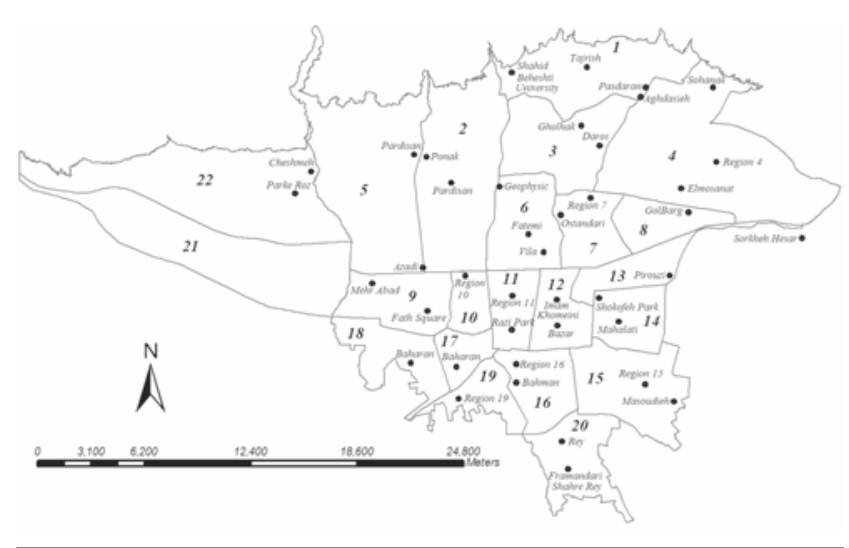

Figure 1. Spatial distribution of monitoring stations in twentytwo urban regions of Tehran, Iran, 2002-2012. 
across the spatial domain of interest - has found its way into the environmental sciences and other disciplines. It is an improvement over inverse distance weighting because prediction estimates tend to be less biased and because predictions are accompanied by prediction standard errors (quantification of the uncertainty in the predicted value) (SEs). The semivariogram captures the spatial dependence between samples by plotting semivariance against separation distance and is the basic tool for geostatistics and Kriging.

The three basic Kriging methods differ as follows. First, OK assumes absence of drift. It focuses on the spatially correlated component and uses the fitted semivariogram directly for interpolation. Second, UK assumes that the spatial variation in $\mathrm{z}$ values has drift or a trend in addition to spatial correlation between sample points. Third, SK assumes that means of the dataset is known.

The premise of any spatial interpolation is spatial autocorrelation, i.e. close samples tend to be more similar than distant samples, and property of spatial data is implicitly used in IDW. In Kriging, one must model the spatial autocorrelation using a semivariogram instead of assuming a direct, linear relationship with separation distance. The root mean square error (RMSE) and mean error (ME) validation parameters are used to compare different interpolation techniques, which can be calculated by the following equations:

$$
\begin{aligned}
M E & =\frac{1}{N} \sum_{i=N}^{N}\left\{z\left(x_{i}\right)-\hat{Z}\left(x_{i}\right)\right\} \\
R M S E & =\sqrt{\frac{1}{N} \sum_{i=N}^{N}\left\{z\left(x_{i}\right) \hat{Z}\left(x_{i}\right)\right\}^{2}}
\end{aligned}
$$

where, $\hat{\mathrm{Z}}\left(x_{i}\right)$ is the predicted value, $z\left(x_{i}\right)$ the observed (known) value, $\mathrm{N}$ the number of values in the dataset and $\sigma^{2}$ the Kriging variance for location $x_{i}$ (Webster and Oliver, 2001). The less the value arrived at by these calculations, the better the model. These validation parameters were applied to all of the interpolation techniques applied in this research.

\section{The sequential non-parametric Mann-Kendall test}

The sequential non-parametric Mann-Kendall test (SNMKT) is used to test for trend significance and abrupt detection in time series. By applying this test on a time series, one can detect the existence and significance of any trend in the data. SNMKT is mainly used in environmental science because it is a simple, robust test that can be used to statistically assess if there is a monotonic upward or downward trend of the variable of interest over time. In other words, the test typically is used for a more specific purpose to determine whether the central value or median changes over time. The spread of the distribution must remain constant, though not necessarily in the original units. If a monotonic transformation such as the ladder of powers is all that is required to produce constant variance, the test statistic will be identical to that of the original units. This statistic is highly recommended for general use by the World Meteorological Organization (WMO), because it detects time series trends without requiring normality or linearity (Wang et al., 2008). The SNMKT has to be done in several steps. First, the data are ranked and $\mathrm{t}_{i}$, i.e. the ratio of rank of $t$ to the ranks before it, is calculated and after that the cumulative frequency of $t_{i}$, i.e. $\Sigma t_{i} . E_{i}$ (the mathematical expectancy $V_{i}$ or the variance) and $U_{i}$, i.e. the com- parative SNMKT index, are calculated by the following equations:

$$
\begin{gathered}
E_{i}=\frac{n_{i}\left(n_{i}-1\right)}{4} \\
V_{i}=\frac{n_{i}\left(n_{i}-1\right)\left(2 n_{i}+5\right)}{72} \\
U_{i}=\frac{\left(\sum t_{i}-E_{i}\right)}{\sqrt{V_{i}}}
\end{gathered}
$$

In the equations above, $n_{i}$ is the time-order of the data. The index of $U_{i}$ has a normal distribution. Because of this, the normal curve table is consulted to detect and test the significance of the trend.

To draw the SNMKT graph and realise the degree of significance of the time series trend, the symmetric statistics $\left(E_{i}^{\prime}, V_{i}^{\prime}\right.$ and $\left.U_{i}^{\prime}\right)$ must first be calculated. The equations are as follows:

$$
E_{i}=\frac{\left[N-\left(n_{i}-1\right)\right]\left(N-n_{i}\right)}{4}
$$

$$
V_{i}^{\prime}=\frac{\left.\left.\left.\left\lfloor N-\left(n_{i}-1\right)\right\rfloor\left(N-n_{i}\right)\right\rfloor 2\left(N-n_{i}\right)\right)\right\rfloor+5}{72}
$$

$$
E_{i}=\frac{n_{i}\left(n_{i}-1\right)}{4}
$$

where: $N$ is the statistical duration, or the sample size. The confluence of $U_{i}$ and $U_{i}^{\prime}$ in the certainty scope of \pm 1.96 (the $5 \%$ level) indicate significant changes in the time series and the behaviour of $U_{i}$ after the confluence determines the descending or ascending state of the series. Graphs in which the $U_{i}$ and $U_{i}^{\prime}$ lines do not cross, i.e. lack of confluence, represents an indication that the series does not have a trend (Ghavidel and Ahmadi, 2015)

\section{Polynomial trend lines}

With larger amounts of data, trends become less linear and tend to fluctuate, which is an indication that a polynomial trend has taken over (Ghavidel, 2012). A polynomial trend is useful, for example, when analyzing gains and losses over a large expanse of data. These functions are sometimes expressed as Legendre polynomials, where the order is determined by how many times the direction of the curve changes, i.e. the number of hills and valleys. For example, a second order Legendre polynomial trend line has only one change of direction, while an third order one has two. Polynomial regression models are usually fitted using the method of least squares, which minimizes the variance of the unbiased estimators of the coefficients under the conditions of the Gauss-Markov theorem (Baily, 1993). Polynomial trend models are useful in situations where the analyst knows that curvilinear effects are present in the true response function. With a polynomial model type, we can select a degree between 2 and 8 , where the higher polynomial degrees exaggerate the differences between the values of the data. When the number of data increases very rapidly, the lower order terms may therefore have little variation compared to the higher order terms, 
a situation that rends the model impossible to estimate accurately. Also, more complicated polynomial models of higher order require more data to estimate properly (Ghavidel, 2012). To find the relation between the $\mathrm{AQI}$ and each pollutant and to disclose the amount of each in the index, linear regression was applied. In this method, AQI was the dependent variable (A), with the pollutants as the independent ones and the method applied was the multiple regression.

\section{Results}

\section{Time series analysis of Tehran's daily air quality index}

After calculating and forming the daily time series of the Tehran AQI, the characteristics related to the descriptive statistical parameters of the time series were extracted (Table 1). The most important indicator in Table 1 is the long-term daily average (of all the 4018 study days) of the AQI, which shows that in the long-term Tehran's air is in fact normal for most of the days, even if it is at the end of the normal average range. However, the fact is that the mean of Tehran's AQ, calculated based on the arithmetic mean, is not suitable and that the average AQ indicates that $\mathrm{AQ}$ is neither good nor dangerous. Indeed, the long-term average value of 88 is unsuitable for seniors, children and people with heart and/or lung disease and it indicates that Tehran $A Q$ is not as good as desired. The frequency of occurrence of large returns in a particular direction is measured by skewness (Skew). This indicator is used in distribution analysis as a sign of asymmetry and deviation from a normal distribution; in other words, Skew measures the degree of asymmetry of a distribution around its mean. The positive Skew of Tehran's $\mathrm{AQI}$ data indicates a distribution with an asymmetric tail extending towards more positive values. With attention to the estimated Skew parameter value that amounts to 63 , it was found that most AQI data were concentrated left of the mean, with extreme values to the right (right-skewed distribution). Tehran's AQI data have a big range (352) that was calculated from differences between the minimum (4 April 2004 with the $\mathrm{AQI}=29$, i.e. an acceptable $\mathrm{AQ}$ ) and the maximum (5 July 2009 with the $\mathrm{AQI}=381$, i.e. a hazardous $\mathrm{AQ}$ ). The mode of $\mathrm{AQI}$ daily data was 61 , which shows that an $\mathrm{AQI}=69$ had the highest frequency of occurrence. The calculated long-term standard deviation (SD) for Tehran's daily AQI data reached 29 . This estimated value for the SD measures how concentrated the data are around the mean; the more concentrated, the smaller the SD. The coefficient of variation (CV) is

Table 1. Descriptive statistical parameters of the Theran longterm daily air quality index, 2002-2012.

\begin{tabular}{lc} 
Variable & Value \\
Study days (n) & 4018 \\
Mean & 88 \\
\hline SD & 29 \\
CV & 33 \\
\hline Minimum & 29 \\
Median & 83 \\
\hline Maximum & 381 \\
Range & 352 \\
\hline Mode & 61 \\
Skew & 63
\end{tabular}

SD, standard deviation; CV, coefficient of variance; Skew, skewness. the other indicator that indicates a measure of the dispersion of data points in a data series around the mean. The coefficient of variation represents the ratio of the $\mathrm{SD}$ to the mean. The estimated $\mathrm{CV}$ rate for Tehran's daily AQI data reached $33 \%$. Tehran's AQI is a reflection of the temporal variation of air pollutants. Figure 2 shows that the temporal variation of Tehran $\mathrm{AQ}$ trend has been increasing over the total study period. The normal range of the $\mathrm{AQI}$ varied between 59 as the lower limit (index mean-SD) and 117 as the upper limit (index mean+SD) with figures above the higher limit taken as polluted days and those less than the lower limit considered as clean. As shown in Figure 2, the line marking the temporal variations of Tehran's AQI shows a positive temporal variation of about $11.8 \%$ with a second order Legendre polynomial. The fitted second-order Legendre polynomial trend, positive slope of the trend line and coefficient of determination $\left(R^{2}\right)$ as a goodness of fit model mean that the annual maximum AQI will show increase with a high statistical probability in the coming years. The fact that the SNMKT showed a line collision $\left(U_{i}\right.$ and $\left.U_{i}^{\prime}\right)$ in the certainty scope of $95 \%( \pm 1.96)$ indicates a significant variations of series (Figure 3). Ui was seen to be ascending and thus the increasing trend of Tehran's AQI should continue in this direction in the future with 95\% probability. As shown in Figure 4, the maximum AQI has been in an annually increasing trend over the whole period following a secondorder Legendre polynomial and Figure 5 confirms this trend. From Figure 6 , it can be concluded that in terms of the frequency of occur-

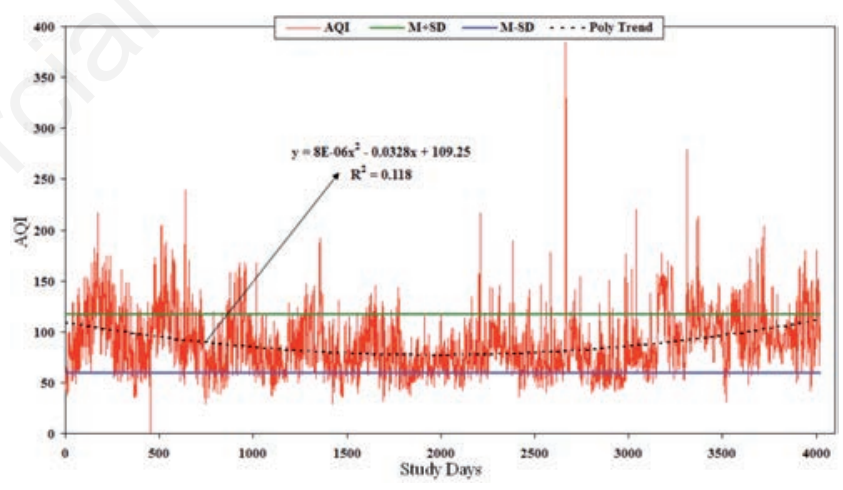

Figure 2. The temporal variation of Tehran's air quality index, 2002-2012.

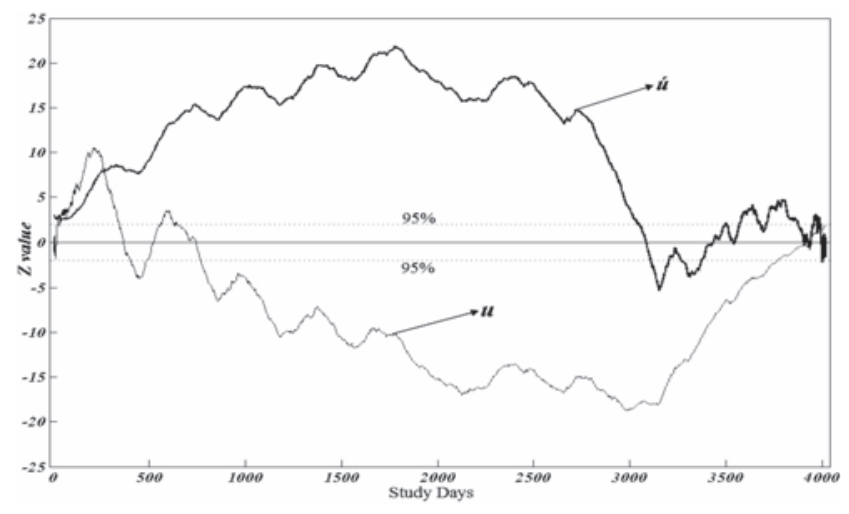

Figure 3. The sequential non-parametric Mann-Kendall test for Tehran air quality index, 2002-2012. 
rence of the various classes of $\mathrm{AQ}$, the weather condition had a generally poor quality for 1191 days (1 hazardous, 10 very unhealthy, 176 unhealthy and 1003 days unhealthy for sensitive groups). Although the weather was classified as good for 189 days and healthy for 2639 days in the remaining 2826 days ( $70.3 \%$ of the period), it must be concluded that it was unacceptable in $29.7 \%$ of the study period.

The frequency of occurrence of each of the classes of Tehran's AQ standards for six categories and their contribution percentage were calculated (Table 2). The temporal trends of annual frequencies of each of the $\mathrm{AQ}$ classes for six categories were also calculated (Figure 7; category hazardous is not provided as trend analysis could not be done on the basis of 1 hazardous day only), which shows that $64.8 \%$ of the temporal variations of the annual good category and $64.1 \%$ of the moderate (healthy) category can be explained by the decreasing polynomial trend. In other words, the number of good and healthy days decreased in the study period. The temporal variation of other categories (unhealthy for sensitive groups, unhealthy and very unhealthy) was thus positive and increasing.

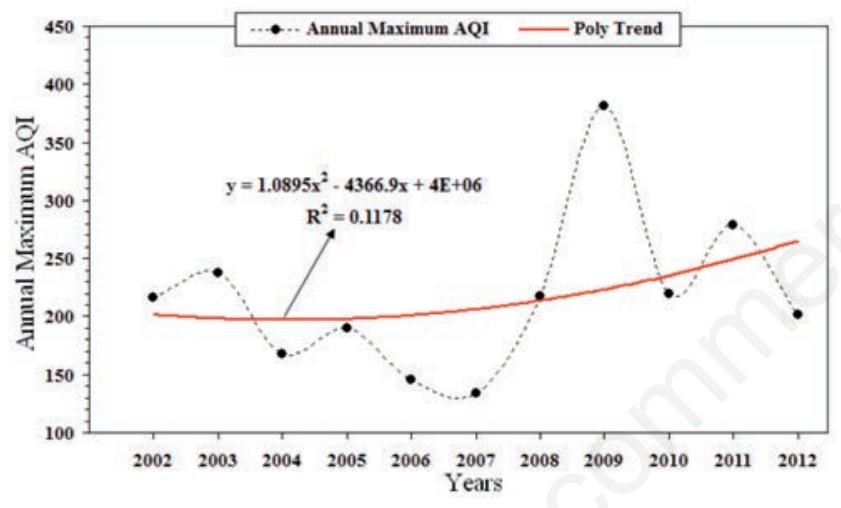

Figure 4. The temporal variation in annual maximum of Tehran's air quality index, 2002-2012.

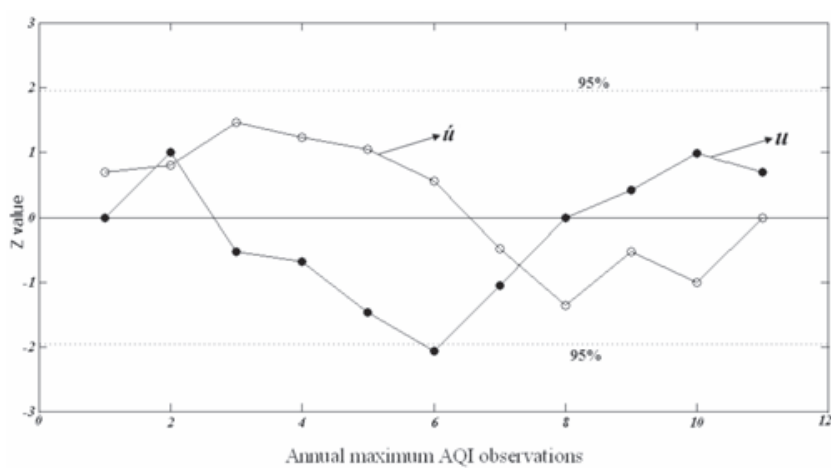

Figure 5. Significant annual maximum variation of Tehran's air quality index using sequential non-parametric Mann-Kendall test.

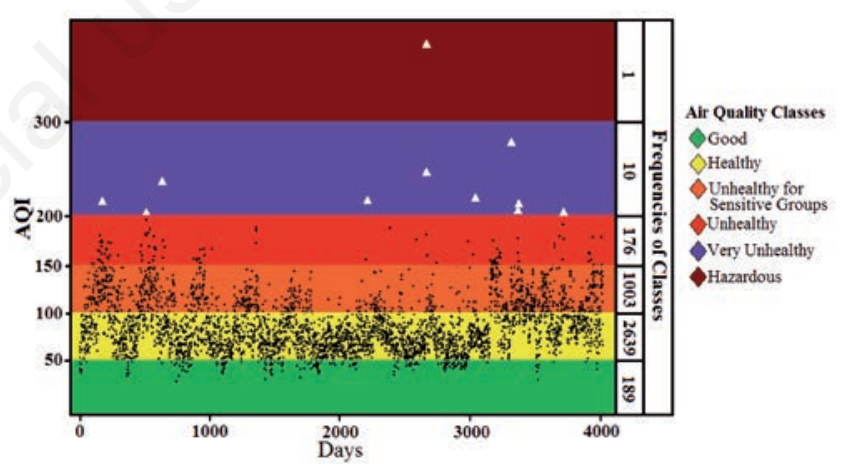

Figure 6. Classification of Tehran's air quality index for each of the six main standard classes.

Table 2. The Tehran annual air quality classes and frequencies in the period 2002-2012.

\begin{tabular}{|c|c|c|c|c|c|c|c|}
\hline $\begin{array}{l}\text { Category } \\
\text { AOI values }\end{array}$ & $\begin{array}{c}\text { Good } \\
0-50\end{array}$ & $\begin{array}{l}\text { Moderate } \\
51-100\end{array}$ & $\begin{array}{c}\text { Unhealthy* } \\
101-150\end{array}$ & $\begin{array}{l}\text { Unhealthy } \\
151-200\end{array}$ & $\begin{array}{l}\text { Very unhealthy } \\
201-300\end{array}$ & \begin{tabular}{cc}
\multicolumn{3}{c}{ Hazardous } \\
$301-400$ & $401-500$
\end{tabular} & Sum of days \\
\hline 2002 & 8 & 187 & 145 & 24 & 1 & 0 & 365 \\
\hline 2003 & 11 & 191 & 140 & 21 & 2 & 0 & 365 \\
\hline $2004^{\circ}$ & 20 & 258 & 11 & 7 & 0 & 0 & 366 \\
\hline 2005 & 23 & 253 & 86 & 3 & 0 & 0 & 365 \\
\hline 2006 & 36 & 254 & 75 & 0 & 0 & 0 & 365 \\
\hline 2007 & 23 & 327 & 15 & 0 & 0 & 0 & 365 \\
\hline $2008^{\circ}$ & 13 & 293 & 57 & 2 & 1 & 0 & 366 \\
\hline 2009 & 32 & 291 & 36 & 4 & 1 & 1 & 365 \\
\hline 2010 & 14 & 238 & 88 & 24 & 1 & 0 & 365 \\
\hline 2011 & 6 & 140 & 209 & 7 & 3 & 0 & 365 \\
\hline $2012^{\circ}$ & 3 & 207 & 141 & 14 & 1 & 0 & 366 \\
\hline Total (n) & 189 & 2639 & 1003 & 176 & 10 & 1 & 4018 \\
\hline$\%$ & 4.7 & 65.67 & 24.96 & 4.38 & 0.25 & 0.02 & 100 \\
\hline
\end{tabular}

$\mathrm{AQI}$, air quality index. *Only for sensitive groups; leap year. 


\section{Spatial distribution of air pollution in Tehran}

The main air pollutant in the most polluted days of the year is the $\mathrm{PM}_{10}$. Therefore, 10 daily averages (a composite of 10 days classified as a very unhealthy $\mathrm{AQ}$ ) due to pollution (200-300 parts per million) were plotted to show the AQI spatial distribution for the 22 urban regions of Tehran during these days (Figure 8). In all the selected days that $\mathrm{PM}_{10}$ was responsible for air pollution, dust storm occurred (Table 3). It can be seen that $\mathrm{PM}_{10}$ pollutants in Tehran dominated in the Centre-East of the city with less such pollution in the North and the very South, which is shown in Figure 8 with the focus in regions number $6,7,9,10,11$, $12,14,17$ and 18 as well as parts of regions number $2,3,4,5,15,16$, 19, 21 and 22. Thus, the $\mathrm{PM}_{10}$ pollutants enter Tehran from the West carried by local winds due to atmospheric barotropic and inversion conditions (an effect of anticyclons) and they remain stable. In recent years, the main reasons for the decreasing trends of the AQI in the good and moderate categories and the increasing trends in the unhealthy and hazardous categories in Tehran are: i) use of substandard gasoline that does not meet international standards (main reason), which is available in fuel stations of Tehran and the rest of Iran; ii) use of vehicles, especially motorcycles, with sub-optimal environmental motor standards; and iii) road dust (with a share of $95.4 \%$ of the total outdoor $\mathrm{PM}_{10}$ emission in Tehran) that originate from the friction between tires and asphalt and aerosols from the interior deserts of Iran, Middle East and even Africa.

Table 3. The results of interpolation methods used.

\begin{tabular}{lcc} 
Model & RMSE & MIE \\
IDW & 81.66 & 15.69 \\
GPI & 90.21 & 0.73 \\
\hline LPI & 109.30 & 22.30 \\
RBF & 80.90 & 5.68 \\
\hline SK & 89.90 & 4.18 \\
OK & 80.87 & 3.10 \\
\hline UK & 91.50 & 3.22 \\
\hline
\end{tabular}

RMSE, root mean square error; ME, mean error; IDW, inverse distance weighting; GPI, global polynomial interpolation; LPI, local polynomial interpolation; RBF, radial basis function; SK, simple Kriging; OK, ordinary Kriging; UK, universal Kriging.
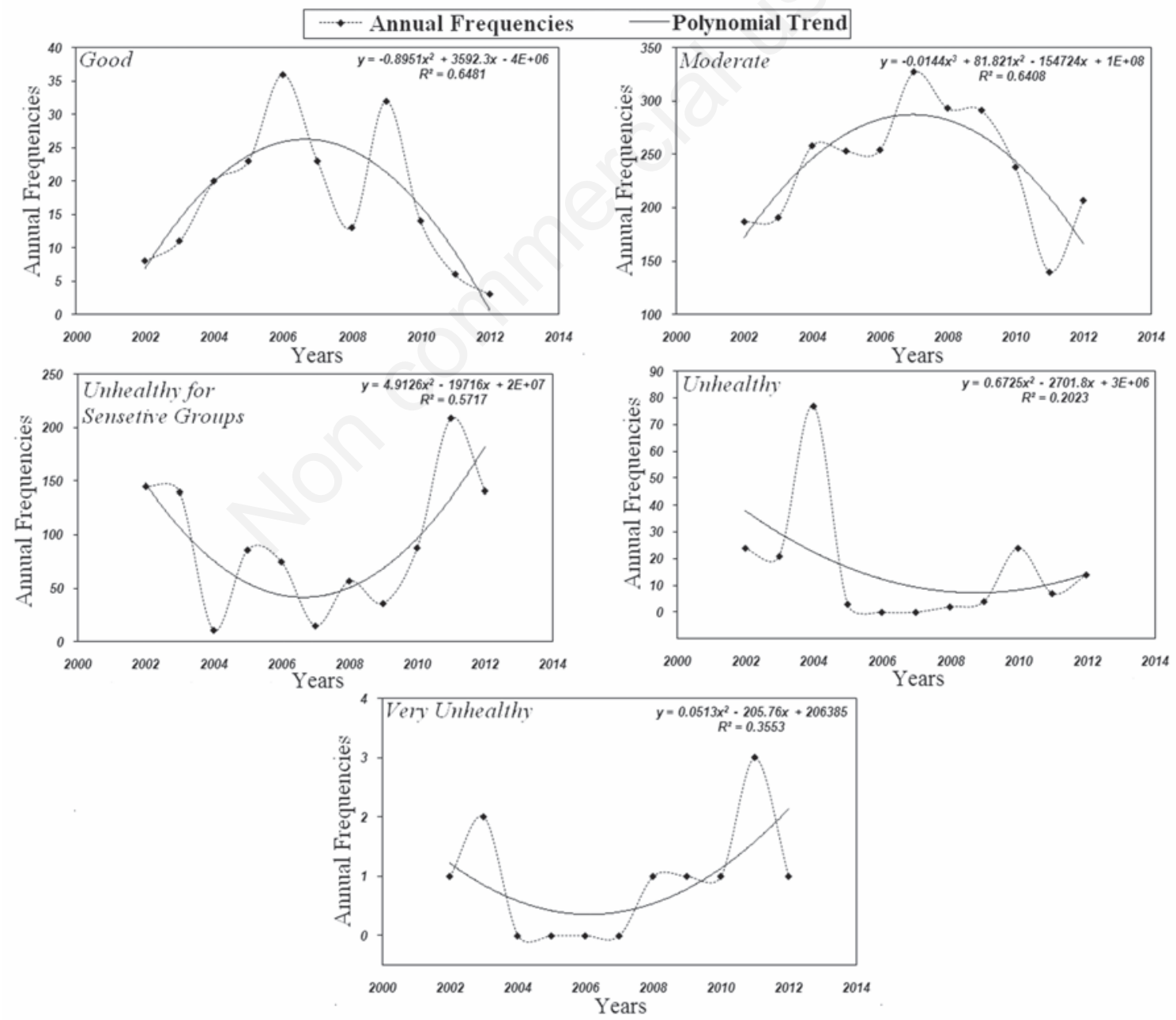

Figure 7. The temporal variation in annual frequencies of each air quality standard category in Tehran. 


\section{Calculating the relation between air quality index and pollutants}

Here, the $\mathrm{R}^{2}$ was found to be 0.985 , which shows that $98.5 \%$ of variations of the dependent variable (A) can be explained by the independent variables. This coefficient is shown in Table 4. Significance of regression and linear relationship between the variables were checked by applying the analysis of variance (ANOVA) test. The obtained $\mathrm{P}$ values, which approve or reject the significance of regression or linear relationship between variables with a $95 \%$ confidence level, are shown in Table 5. Considering these values, it can be concluded that the regression was significant and there was a linear relationship between variables; in other words, the assumption of the significance of regression and the linear relationship between variables could be accepted at the confidence level of $95 \%$. The main results of regression are displayed by the coefficients in Table 6 . Here, the T-test statistic is shown as calculated for individual regression coefficients (Rs) including their significance levels. Given the values of significance level, the variables with significant effects can be found. The regression equation can be written based on B values in the table. Given the significant level, the equation representing the obtained regression model is as follows:

$$
\mathrm{y}=1.218+0.51(\mathrm{CO})+0.207\left(\mathrm{PM}_{10}\right)+0.853\left(\mathrm{PM}_{2.5}\right)
$$

Nevertheless, the beta values should be used to find the importance and role of independent variables in the regression equation, as these

Table 4. Sum of the coefficients of determination for the regression model.

\begin{tabular}{|c|c|c|c|c|c|}
\hline \multirow[t]{2}{*}{$\mathbf{R}$} & \multirow[t]{2}{*}{$\mathrm{R}^{2}$} & \multirow[t]{2}{*}{ Adjusted $\mathbf{R}^{2}$} & \multirow[t]{2}{*}{$\begin{array}{l}\mathrm{R}^{2} \text { change } \\
\mathrm{SE}\end{array}$} & \multicolumn{2}{|c|}{ Change statistics } \\
\hline & & & & $R^{2}$ change & F change \\
\hline 0.992 & 0.985 & 0.985 & 3.383 & 0.985 & 9856.006 \\
\hline
\end{tabular}

$\mathrm{R}^{2}$, coefficient of determination; $\mathrm{SE}$, standard error; F, F statistics.

Table 5. Results of analysis of variance for fitted multiple regression.

\begin{tabular}{lccccc} 
Model & SS & DF & MS & F & P \\
Regression & $676,665.927$ & 6 & $112,777.655$ & 9856.006 & 0.000 \\
Residual & $10,298.278$ & 900 & 11.443 & & \\
\hline Total & $686,964.205$ & 906 & & & \\
\hline
\end{tabular}

SS, sum of squares; DF, degree of freedom; MS, mean square; F, F statistics. values are standardized. Thus, they can be applied to judge the relative importance of variables. The high amount of a variable's beta represents its relative importance and its role on A. Thus, it can be said that $\mathrm{PM}_{2.5}$ had the highest effect on Tehran's AQ.

\section{Discussion}

There has been no serious study of the AQI trend and impacts of air pollution in Tehran. The most obvious expected effects are those related to human health. Air pollutants, mainly particulate matters, are a major cause of respiratory and cardiovascular diseases, which are highly prevalent in Tehran, particularly in the central business district. The effects of other pollutants on inner city residents are also expected to be considerable. From the geographical point of view, Tehran is wedged between two mountain ranges that trap the fumes of its bumper-to-bumper traffic. The main reason for air pollution is the low standard of gasoline used and emissions from vehicles using low quality and non-standard gasoline. However, the issue of air pollution is very complex and needs detailed further studies as it comes from various sources and as the atmosphere tends to transform it.

The fact that the pollution in Tehran enters from the West and moves in an easterly direction towards the city centre means that pollution concentrations are lower in the northern and southern parts of the city. The regression analysis showed that $\mathrm{PM}_{2.5}, \mathrm{PM}_{10}$ and $\mathrm{CO}$ influenced the

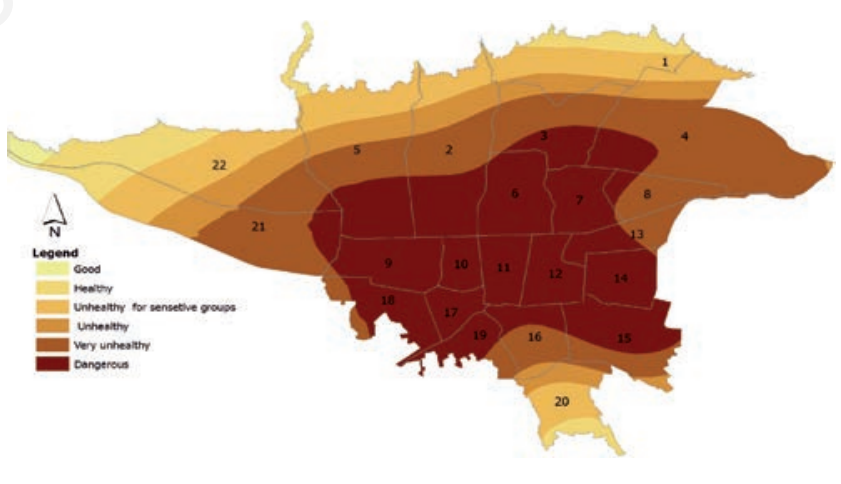

Figure 8. Map showing the average risk distribution in Tehran during ten days due to $\mathrm{PM}_{10}$ pollutants.

Table 6. Coefficients and model estimations for multiple regression.

\begin{tabular}{|c|c|c|c|c|c|}
\hline \multirow[t]{2}{*}{ Model } & \multicolumn{2}{|c|}{ Non-standardised coefficients } & \multirow{2}{*}{$\begin{array}{c}\text { Standardised coefficients } \\
\text { Beta }\end{array}$} & \multirow[t]{2}{*}{ T-statistics } & \multirow[t]{2}{*}{$\mathbf{P}$} \\
\hline & Beta & SE & & & \\
\hline Constant & 1.218 & 0.770 & - & 1.582 & 0.114 \\
\hline $\mathrm{CO}$ & 0.051 & 0.011 & 0.025 & 4.512 & 0.000 \\
\hline $\mathrm{O}_{3}$ & -0.013 & 0.009 & -0.006 & -1.424 & 0.155 \\
\hline $\mathrm{NO}_{2}$ & -0.012 & 0.010 & -0.007 & -1.178 & 0.239 \\
\hline $\mathrm{SO}_{2}$ & -0.008 & 0.026 & -0.002 & -0.317 & 0.752 \\
\hline $\mathrm{PM}_{10}$ & 0.207 & 0.010 & 0.157 & 19.844 & 0.000 \\
\hline$\underline{\mathrm{PM}_{2.5}}$ & 0.853 & 0.009 & 0.855 & 94.921 & 0.000 \\
\hline
\end{tabular}

SE, standard error. 
$\mathrm{AQ}$ of Tehran the most, and the largest contribution of pollutants was of the $\mathrm{PM}_{2.5}$ kind (coefficient of 0.853 ). It was therefore not surprising that Tehran's $\mathrm{AQ}$ had been reduced by approximately $11.8 \%$ between 2002 and 2012, a strongly decreasing trend that indicates that it will continue in the coming years. The frequency distribution of days with good and average quality reveals that the trend of such days declined severely during the study period. With the strong downward sloping trend of the time series, it is highly likely that the number of good (clean) days will be greatly reduced in the future.

\section{Conclusions}

According to the classification of AQ standards and the position of each study day in the classification presented in Table 1, it can be said that Tehran is not very good for life in general.

Statistical analysis of Tehran air quality index shows that Tehran air quality was not a good condition during the 11-year period from 2002 to 2012 and generally during the studied 4018 days air quality was considered unhealthy in 1190 days (29.6\%). In the 2828 remaining days $(70.4 \%)$, the weather has been in a state of healthy and good qualities.

The general trend of daily air quality index of Tehran in the 11-year studied period showed an upward trend which points to a $12 \%$ decrease in Tehran's air quality. The mentioned trend is meaningful and shows that in the coming years, there will probably be a decrease of $12 \%$ for Tehran AQI.

\section{References}

Baily WN, 1993. On the product of two Legendre polinomials. PCPS-P Camb Philos S 29:173-7.

Bandeira JM, Coelho MC, Elisa Sá M, Tavares R, Borrego C, 2011. Impact of land use on urban mobility patterns emissions and air quality in a Portuguese medium-sized city. Sci Total Environ 409:1154-63.

Banerjee T, Singh SB, Srivastava RK, 2011. Development and performance evaluation of statistical models correlating air pollutants and meteorological variables at Pantnagar. India Atmos Res 99:505-17.

Bohler T, Karatzas K, Peinel G, Rose T, San Jose R, 2002. Providing multimodal access to environmental data-customizable information services for disseminating urban air quality information in APNEE. Comput Environ Urban 26:39-61.

Branis M, 2009. Air quality of Prague: traffic as a main pollution source. Environ Monit Assess 156:377-90.

Chan TC, ML Chen, Lin F, Lee CH, Chiang PH, Wang DW, Chuang JH, 2009. Spatiotemporal analysis of air pollution and asthma patient visits in Taipei, Taiwan. Int J Health Geogr 8:1-10.

Chang CS, Lee CT, 2007. Evaluation of the trend of air quality in Taipei, Taiwan from 1994 to 2003. Environ Monit Assess 127:87-96.

Chattopadhyay S, Gupta S, Saha RN, 2010. Spatial and temporal variation of urban air quality: a GIS approach. J Envir Protect Sci 1:264-77.

Dockery DW, Pope CA, 1994. Acute respiratory effects of particulate air pollution. Annu Rev Publ Health 15:107-32.

Firdaus G, Ateeque A, 2011. Changing air quality in Delhi, India: determinants, trends, and policy implications. Reg Environ Change J 11:74352.

Gharagozlou A, Tayeba A, Dadashi M, Abdolahi H, 2014. Zoning of CO emissions in Tehran in the medium term by using third quartile as the exposure candidate. J Geogr Inf Syst 6:526-32.
Ghavidel Y, 2012. Statistical research on analyzing the oscillations and forecasting the time series of Tehran high extreme temperatures. Geogr Plann 39:109-28.

Ghavidel Y, Ahmadi M, 2015. Statistical analysis and temporal trend of annual maximum temperatures of Abadan in Southwestern of Iran. Arab J Geosci 8:8219-28.

Gupta AK, Karar K, Ayoob S, John K, 2008. Spatio-temporal characteristics of gaseous and particulate pollutants in an urban region of Kolkata. India Atmos Res 87:103-15.

Hyun Shin H, Burnett RT, Stieb DM, Jessiman B, 2009. Measuring public health accountability of air quality management. Air Qual Atmos Health 2:11-20.

Junk J R, Helbig A, Lüers J, 2003. Urban climate and air quality in Trier Germany. Int J Biometeorol 47:230-8.

Kassomenos P, Papaloukas C, Petrakis M, Karakitsios S, 2008. Assessment and prediction of short term hospital admission: the case of Athens, Greece. Atmos Environ 42:7078-86.

Kumar A, Goyal P, 2011. Forecasting of air quality in Delhi using principal component regression technique. Atmos Pollut Res 2:436-44.

Lary DJ, Faruque FS, Malakar N, Moore A, Roscoe R, Adams ZL, Eggelston Y, 2014. Estimating the global abundance of ground level presence of particulate matter $\left(\mathrm{PM}_{2.5}\right)$. Geospat Health 8:611-30.

Mage D, Ozolins G, Peterson P, Webster A, Orthofer R, Vandeweerd V, Gwynne M, 1996. Urban air pollution in mega cities of the world. Atmos Environ 30:681-6.

Mintz D, 2009. Technical assistance document for the reporting of daily air quality - the air quality index (AQI). US EPA Office of Air Quality Planning and Standards, Research Triangle Park, NC, USA.

Mohan M, Kandya A, 2007. An analysis of the annual and seasonal trends of air quality index of Delhi. Environ Monit Assess 131:267-77.

Moradi Dashtpagerdi M, Sadatinejad SJ, Zare Bidaki R, Khorsandi E, 2014. Evaluation of air pollution trend using GIS and RS applications in South West of Iran. J Indian Soc Remote Sen 42:179-86.

Naddafi K, Hassanvand MS, Momeniha F, Nabizadeh R, Faridi S, 2012. Health impact assessment of air pollution in megacity of Tehran, Iran. Iran J Environ Health Sci Eng 9:28.

Nastos PT, Paliatsos AG, Anthracopoulos MB, Roma ES, Priftis KN, 2010. Outdoor particulate matter and childhood asthma admissions in Athens, Greece: a time-series study. Environ Health 45:1-9.

Shu J, Dearing JA, Morse AP, Yu LZ, Yuan N, 2001. Determining the sources of atmospheric particles in Shanghai, China, from magnetic and geochemical properties. Atmos Environ 35:2615-25.

Singh KP, Gupta S, Rai P, 2013. Identifying pollution sources and predicting urban air quality using ensemble learning methods. Atmos Environ 80:426-37.

Vanos JK, Hebbern C, Cakmak S, 2014. Risk assessment for cardiovascular and respiratory mortality due to air pollution and synoptic meteorology in 10 Canadian cities. Environ Pollut 185:322-32.

Wang W, Chen X, Shi P, van Gelder PHAJM, 2008. Detecting changes in extreme precipitation and extreme stream flow in the Dongjiang River Basin in southern China. Hydrol Earth Syst Sc 12:207-21.

Webster R, Oliver MA, 2001. Geostatistics for environmental scientists. John Wiley and Sons, Brisbane, Australia.

Wise EK, Comrie AC, 2005. Meteorologically adjusted urban air quality trends in the Southwestern United States. Atmos Environ 39:2969-80.

Yao L, Lu N, 2014. Spatiotemporal distribution and short-term trends of particulate matter concentration over China, 2006-2010. Environ Sci Pollut Res 21:9665-75.

Zhao SQ, Da LJ, Tang ZY, Fang HJ, Song K, Fang JY, 2006. Ecological consequences of rapid urban expansion: Shanghai. China Front Ecol Environ 4:341-6. 